\title{
Vassilis Koutkias (1975 - 2019) - the Painful Loss of a Rare Person
}

\author{
Régis Beuscart, Jacques Bouaud, Marie-Christine Jaulent, and Brigitte Séroussi
}

Vassilis G. Koutkias died on December 14, 2019, at the age of 44. He leaves his wife Andigoni, his two little girls ( 9 and 7 years-old), and a brilliant career as a young scientist in Biomedical Informatics.

Vassilis was born on May 20, 1975, in Lamia, Greece. In 1993, he was accepted to the Department of Electrical and Computer Engineering of the Aristotle University of Thessaloniki in Greece (AUTH). From AUTH, he received a Master degree of Sciences (MSc) in Medical Informatics in January 2001 and a PhD degree in Medical Informatics with a dissertation titled "Information Management and Processing in Distributed Biomedical Information Systems via Autonomous Agents". This dissertation was the first step of his total commitment to research in Biomedical Informatics.

He started his professional career in 1998 as a software developer in the Information Processing Laboratory of the Faculty of Engineering at AUTH. During his graduate studies, he continued to work in the domain of Information and Communication Technologies (ICT) in health in the Laboratory of Computing and Medical Informatics at AUTH; he participated in various pioneering projects in home care, mHealth, and eHealth systems, as well as patient safety informatics.

He first met Pr Régis Beuscart, head of the CERIM Laboratory (Center of Studies and Research in Medical Informatics) in Lille, France, as they both worked on a European Project named PSIP (2007-2009) that was devoted to the automatic identification and prevention of Adverse Drug Events (ADEs) and adverse reactions to medications. ${ }^{1}$ Vassilis collaborated closely on this project and on additional related projects during eight years, working on data collection, data analysis, and the implemen-

PSIP: https://cordis.europa.eu/project/ $\mathrm{id} / 216130 / \mathrm{fr}$ tation of artificial intelligence approaches to solve ADE prevention. Vassilis and Régis continued a fruitful scientific collaboration with visits and exchanges beyond these collaborative projects. Vassilis was very innovative far beyond the limited scope of the different contracts.

In 2012, Vassilis asked Marie-Christine Jaulent, head of the LIMICS (Laboratory of Medical Informatics and Knowledge Engineering for eHealth) in Paris, France, to collaborate on the SAFER project. ${ }^{2}$ The project was focused on pharmacovigilance with a major emphasis in reinforcing signal detection through knowledge engineering technology. For this work, Vassilis was awarded an individual, intra-European, Marie Curie fellowship conducted at the LIMICS. Thus, he moved to France with his family and spent two years in the lab. During these years, Vassilis accomplished a lot, not only in terms of scientific research, but he built strong collaborations inside and outside the lab. Once again, after leaving the LIMICS, Vassilis continued to work in close collaboration with Marie-Christine Jaulent.

After his departure from France, Vassilis came back to Greece in 2016 as a Grade $\mathrm{C}$ researcher in the Centre for Research \& Technology, Hellas - CERTH/INAB. He supervised a large number of MSc students in Medical Informatics and started to supervise $\mathrm{PhD}$ students from 2017, developing the interest of many students for the domain of Biomedical Informatics. He was an excellent lecturer, a coordinator of courses in the MSc degree Program in Medical Informatics, and a thesis supervisor for numerous programs in the Hellenic Open University. Among his colleagues at the CERTH/INAB and AUTH, Vassilis was known as a great colleague and an inspiring supervisor, very

SAFER: https://safer-project.eu/index.html

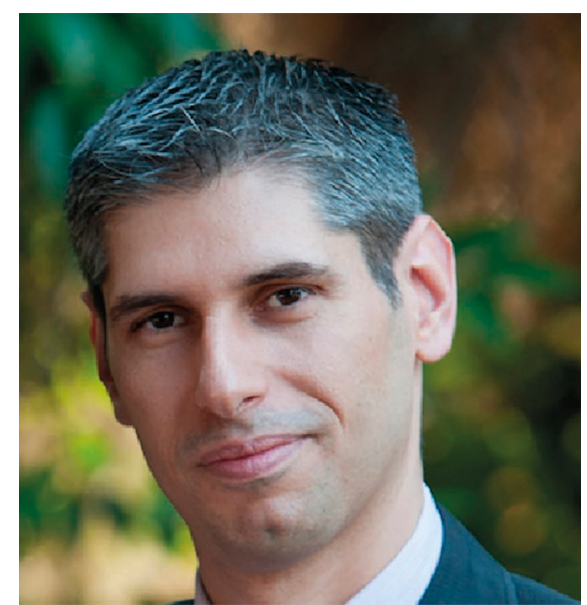

close to colleagues and students, effectively supporting them, always aiming to get "the best out of each single person". Vassilis had the reputation of improving colleagues and students, making them better scientists and always providing them opportunities for their personal accomplishment. He was an example of innate courtesy, selflessness, and integrity.

During his short life, Vassilis has been involved in 15 European projects between 1999 and 2016. He was the Principal Investigator of seven additional European projects between 2017 and 2019, and he was the deputy scientific responsible for CERTH/ INAB for another four European projects between 2016 and 2019. This involvement demonstrates his remarkable intellectual agility, his extraordinary ability to work in various consortiums and on various scientific ICT themes. As the result of this sustained research activity, he was the editor of four books, and author of more than 100 original papers including about 70 papers published in peer-reviewed journals, peer-reviewed papers in books and book series, and peer-reviewed papers published in international conferences proceedings. 
In 2014, Vassilis joined the IMIA Yearbook editorial team as the co-editor of the decision support section. He worked with Jacques Bouaud from 2014 to 2019 and with Catherine Duclos (from September 2019). His co-editors appreciated not only his professional skills, his reliability, and eventually his total commitment to the numerous tasks this role requires, but also his human qualities when interacting with colleagues, essentially his kindness, awareness of others, open-mindedness, fairness, and humility.
Vassilis was an excellent researcher in the field of Biomedical Informatics, "a great husband and a great father proving it every day" as his wife Andigoni describes him. For all of us, he was also a wonderful friend. When Vassilis announced he had an esophageal cancer in January 2017, it was a shock. He made the necessary search to get informed about the best treatments. He came to France to meet the best specialists and had a surgical intervention by Pr. Christophe Mariette in Lille, an internationally renowned surgeon for this kind of

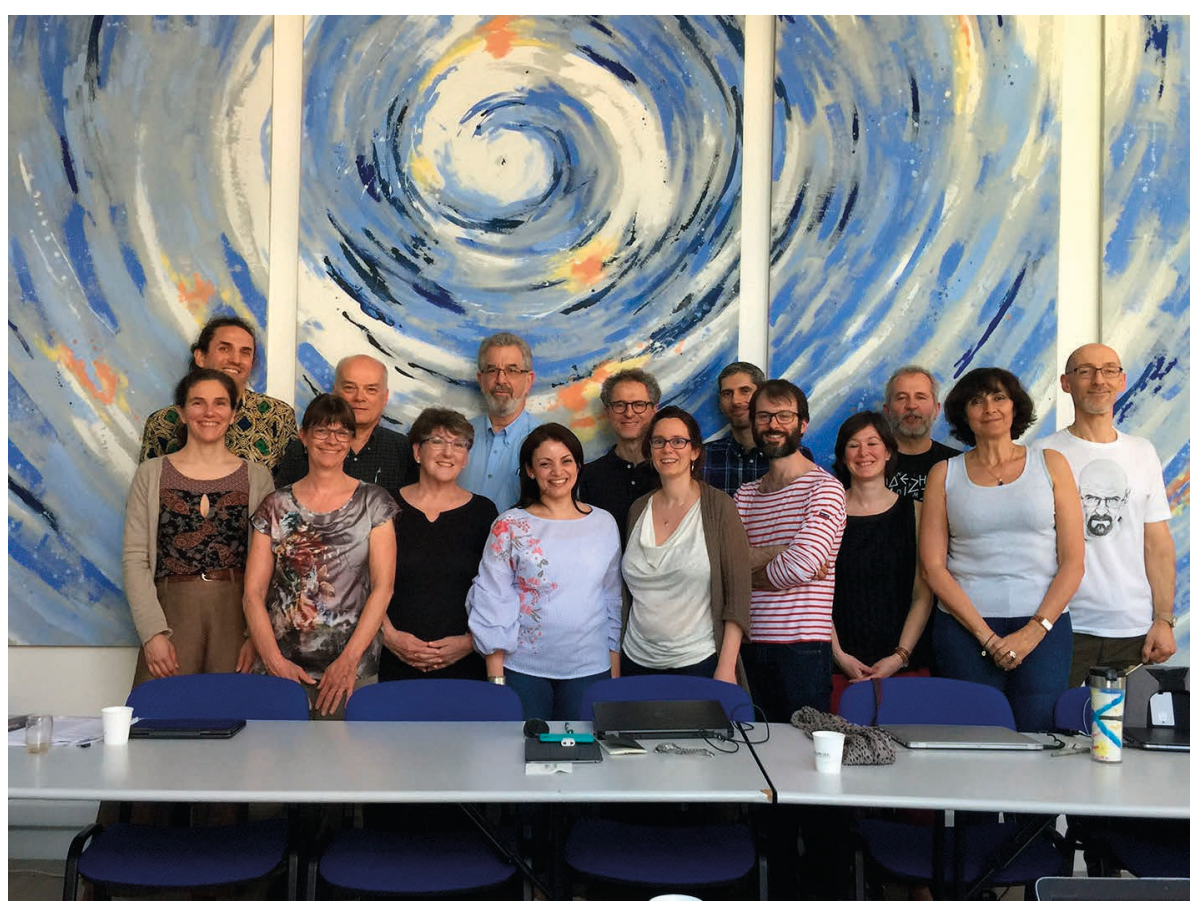

Picture taken at the 2018 IMIA Yearbook selection meeting in Paris, with from left to right, top first then bottom: Adrien Ugon (in charge of the best papers selection), John Holmes (chief editor of the IMIA Yearbook), Kenneth W. Goodman (co-editor of the 2018 Special section) Pierre Zweigenbaum (c0-editor of the Natural Language Processing section), Vassilis Koutkias (co-editor of the Decision Support section), Jacques Bouaud (co-editor of the Decision Support section), Jean Charlet (co-editor of the Knowledge Representation and Management section), Christel Daniel (co-editor of the Clinical Research Informatics section), Martina Hutter (the IMIA Yearbook editorial assistant), Eta S. Berner (co-editor of the Health Information Management section), Lina Soualmia (chief editor of the IMIA Yearbook), Aurélie Névéol (co-editor of the Natural Language Processing section), Ferdinand Dhombres (co-editor of the Knowledge Representation and Management section), Sylvia Pelayo (co-editor of the Human Factors section), and Brigitte Séroussi (chief editor of the IMIA Yearbook and IMIA VP for services). surgery. Despite his serious disease, he never complained. His family and his work were his driving motivations. As he used to say, work was also a means of circumventing the effects of the disease and therapies, a way to spend his time meaningfully and not to sink. Thus, he made a point to continue fulfilling his numerous commitments and even to go on with new things. In 2019, he started the co-supervision with Marie-Christine Jaulent of Pantelis Natsiavas' $\mathrm{PhD}$ thesis on the subject "Novel methods to support active pharmacovigilance in the clinical environment". In 2019, he also announced that he would come to the Yearbook selection meeting in Paris in April, and to MEDINFO 2019 in Lyon to be part of the IMIA Yearbook panel and present the selection of best papers for the decision support section. However, he had to reduce his travels and could not attend. In September 2019, after five IMIA Yearbook issues, and despite his medical condition, he decided to continue as co-editor to ease the transition from Jacques Bouaud to Catherine Duclos for the decision support section. Today, for his sake, the co-supervision of Pantelis Natsiavas' $\mathrm{PhD}$ thesis will be continued with Marie-Christine Jaulent, Andigoni, and the CERTH team, and Jacques Bouaud has accepted to come back to the Yearbook editorial team to work with Catherine Duclos on the decision support section of the IMIA Yearbook.

The passing of Vassilis is a great loss for the Biomedical Informatics scientific community since he was an outstanding researcher and had the profile of the academic teacher bound to develop and disseminate new research and innovations. The passing of Vassilis is also a great loss for all those who had the chance to know him either in Paris, Lille, Thessaloniki (Greece), and beyond within the IMIA Yearbook editorial team. Vassilis was a rare and nice person and if we acknowledge we have been lucky to share few moments with him, we all painfully miss him. 